\title{
The Metabolic Response to Hyperglycaemic Clamping in Insulin-dependent Diabetes
}

\author{
R. Nosadini, G. A. Noy, K. G. M. M. Alberti, A. Hodson, and H. Ørskoy ${ }^{1}$ \\ Department of Clinical Biochemistry and Metabolic Medicine, Royal Victoria Infirmary, Newcastle upon Tyne, England, and Afdeling M, \\ Kommunehospitalet, Aarhus, Denmark
}

Summary. The metabolic and hormonal effects of stable hyperglycaemia $(10-12 \mathrm{mmol} / \mathrm{l})$ have been examined in five insulin-dependent diabetics and compared with the results of $8 \mathrm{~h}(1200$ to $2000 \mathrm{~h})$ normoglycaemic (5-6 mmol/l) clamping. Glucose levels were maintained using a glucose controlled insulin infusion system. Mean blood lactate, pyruvate, total ketone bodies, glycerol and plasma nonesterified fatty acids were similar during the period of stable glycaemia at the two glucose levels. In contrast mean blood alanine was markedly elevated during hyperglycaemic clamping $(0.384 \pm 0.008$ vs $0.298 \pm$ $0.021 \mathrm{mmol} / \mathrm{l}$ ) and 3-hydroxybutyrate was slightly decreased $(0.068 \pm 0.007$ vs $0.084 \pm 0.008 \mathrm{mmol} / \mathrm{l})$. Plasma glucagon levels were raised during hyperglycaemic clamping and growth hormone slightly decreased. There was a close positive correlation between mean blood alanine and mean blood glucose $(\mathrm{r}=0.79, \mathrm{p}<0.01)$, and a negative correlation of alanine with the amount of insulin infused $(r=$ $-0.72, p<0.01)$. It is suggested that the raised alanine results from increased peripheral glucose utilisation. In general a short period of stable hyperglycaemia is not associated with a worsening of metabolic abnormalities in insulin-dependent diabetic subjects.

Key words: Artificial endocrine pancreas, glucose clamping, hyperglycaemia, insulin-dependent diabetes, blood glucose, ketone bodies, alanine, lactate, pyruvate, ketogenesis, insulin, glucagon

In normal young adults blood glucose concentration is closely regulated and despite carbohydrate ingestion generally remains between 4 and $7 \mathrm{mmol} / 1$ [1].
By contrast, conventionally treated insulin-dependent diabetics show both raised mean glucose concentrations and marked fluctuations of glucose levels through the day $[1,2]$.

Considerable metabolic perturbations accompany conventional insulin therapy [2]. Even when glucose concentrations are normalised using a glucose-controlled insulin infusion system (GCIS, 'artificial endocrine pancreas'), intermediary metabolism still shows abnormalities [3]. This has been attributed in part to the hyperinsulinaemia that results when the peripheral rather than the portal route is used to infuse insulin.

The present study was designed to test whether infusing less insulin would result in fewer metabolic abnormalities. Levels of blood intermediary metabolites and hormones were therefore measured under two conditions in insulin dependent-diabetics: [1] normoglycaemia achieved by a high insulin infusion rate and [2] stable hyperglycaemia achieved with less insulin.

\section{Materials and Methods}

\section{Subjects}

Five insulin-dependent diabetics were studied for two $12 \mathrm{~h}$ periods. Details of the subjects are shown in Table 1. None of the subjects had evidence of any disease other than diabetes. None was receiving any medication other than insulin. All gave informed consent for the studies and the Declaration of the Helsinki was adhered to.

\section{Protocol}

Patients received their usual insulin up to and including the day before study. After an overnight fast they remained recumbent from $07.30 \mathrm{~h}$ until the end of the study. A double-lumen cannula (17 gauge, Venflon Viggo AB, Helsinborg, Sweden) was placed in 
Table 1. Clinical data of insulin-dependent diabetic subjects studied

\begin{tabular}{|c|c|c|c|c|c|c|c|c|}
\hline \multirow[t]{2}{*}{ Subject } & \multirow[t]{2}{*}{$\operatorname{Sex}$} & \multirow{2}{*}{$\begin{array}{l}\text { Age } \\
\text { (years) }\end{array}$} & \multirow{2}{*}{$\begin{array}{l}\text { Weight } \\
\text { (kg) }\end{array}$} & \multirow{2}{*}{$\begin{array}{l}\text { Height } \\
(\mathrm{cm})\end{array}$} & \multirow{2}{*}{$\begin{array}{l}\text { Duration of } \\
\text { diabetes } \\
\text { (years) }\end{array}$} & \multicolumn{3}{|c|}{ Usual insulin therapy ${ }^{\mathrm{a}}$ (units) } \\
\hline & & & & & & $08.00 \mathrm{~h}$ & 18. & \\
\hline \multirow[t]{2}{*}{1} & \multirow[t]{2}{*}{$\mathbf{M}$} & \multirow[t]{2}{*}{23} & \multirow[t]{2}{*}{85} & \multirow[t]{2}{*}{195} & \multirow[t]{2}{*}{16} & 24 & 28 & Sol \\
\hline & & & & & & 20 & 12 & Iso \\
\hline 2 & $\mathbf{M}$ & 35 & 66 & 180 & 11 & 44 & - & Lente \\
\hline \multirow[t]{2}{*}{3} & \multirow[t]{2}{*}{ M } & \multirow[t]{2}{*}{27} & \multirow[t]{2}{*}{72} & \multirow[t]{2}{*}{183} & \multirow[t]{2}{*}{12} & 20 & 16 & Act \\
\hline & & & & & & 24 & 8 & Mono \\
\hline \multirow[t]{2}{*}{4} & \multirow[t]{2}{*}{$\mathbf{M}$} & \multirow[t]{2}{*}{34} & \multirow[t]{2}{*}{70} & \multirow[t]{2}{*}{180} & \multirow[t]{2}{*}{3} & 6 & 6 & Act \\
\hline & & & & & & 6 & 4 & Iso \\
\hline \multirow[t]{2}{*}{5} & \multirow[t]{2}{*}{ M } & \multirow[t]{2}{*}{48} & \multirow[t]{2}{*}{64} & \multirow[t]{2}{*}{161} & \multirow[t]{2}{*}{28} & 28 & 12 & Sol \\
\hline & & & & & & 24 & 12 & Iso \\
\hline
\end{tabular}

a Sol: soluble insulin (bovine); Iso: isophane insulin (bovine); Lente: lente insulin (bovine); Mono: Monotard insulin (highly purified porcine); Act: Actrapid insulin (highly purified porcine)

Peak C-peptide response after a normal meal was absent in subjects $1,3,5$ and very low in subjects 2 and 4

a forearm vein and blood withdrawn continuously by the GCIIS (Biostator System, Life Science Instruments, Miles Laboratories, Elkhart, Indiana, USA). Blood was diluted and anticoagulated using heparin (50 units/ml) and disodium EDTA $(20 \mathrm{mmol} / \mathrm{l})$ in saline $(0.154 \mathrm{~mol} / \mathrm{l})$ which was pumped down the outer lumen of the cannula. Blood glucose was measured by the GCIIS in $90 \mathrm{~s}$, and glucose $(200 \mathrm{~g} / 1)$, saline $(0.154 \mathrm{~mol} / \mathrm{l})$ or insulin (160 units/l Haemaccel; Hoechst Pharmaceuticals, Hounslow, U. K.) were infused through an antecubital vein cannula (17 gauge) according to a set of predetermined algorithms [4]. On one occasion blood glucose was set at 4 to $6 \mathrm{mmol} / \mathrm{l}$ and on the other occasion 10 to $12 \mathrm{mmol} / \mathrm{l}$. The order of the two studies was random.

After two baseline venous blood samples had been drawn through a further antecubital vein cannula at 08.25 and $08.30 \mathrm{~h}$ feedback control was instituted with the GCIIS and breakfast was consumed. Lunch was eaten at $12.00 \mathrm{~h}$ and dinner at $18.00 \mathrm{~h}$ with a snack at $10.00 \mathrm{~h}$. Each patient consumed the same carbohydrate, fat and protein on the two occasions. Blood samples were taken every $30 \mathrm{~min}$ until $20.00 \mathrm{~h}$.

\section{Methods}

Approximately $8 \mathrm{ml}$ of freeflowing venous blood were taken at each sample time. One to two $\mathrm{ml}$ was mixed with $5 \%(\mathrm{w} / \mathrm{v})$ perchloric acid, refrigerated immediately and the supernatant used for the enzymatic assay of glucose, 3-hydroxybutyrate, acetoacetate, lactate, pyruvate, alanine and glycerol $[5,6]$, within $24 \mathrm{~h}$. A further $1.5 \mathrm{ml}$ blood was centrifuged immediately and the plasma frozen for assay of non-esterified fatty acids (NEFA) [7]; $2.25 \mathrm{ml}$ were mixed with $0.25 \mathrm{ml}$ of aprotinin $(10000 \mathrm{u} / \mathrm{ml})$ containing $25 \mu \mathrm{mol}$ disodium EDTA, centrifuged and the plasma stored for glucagon assay (8). Serum from the remainder of the blood was stored at $-20^{\circ} \mathrm{C}$ and used for growth hormone [9] and triglyceride estimation [10]. Serum C-peptide levels were measured fasting and $1 \mathrm{~h}$ after breakfast on one occasion [11].

\section{Calculations}

Total ketone bodies refers to the sum of 3-hydroxybutyrate and acetoacetate concentrations. Results are presented as mean \pm SEM. Mean values at each time point were compared using the Student t-test. Logarithmic transformation of ketone body concentration was performed before comparison as it has previously been shown that blood ketone body values are log normally distri- buted [12]. For individual patients mean values for each hormone and metabolite were calculated for the period from $12.00 \mathrm{~h}$ to $20.00 \mathrm{~h}$, as in all cases the selected glucose value had been reached by $12.00 \mathrm{~h}$. Significant differences between the averages of those mean values were sought using the Mann Whitney U-test, because of nonparametric distribution [13]. Correlations between $8 \mathrm{~h}$ mean values for hormones and metabolites were calculated with the Spearman Rank test [13].

\section{Results}

\section{Blood Glucose Concentration and Insulin Administration}

Figure 1 shows the mean blood glucose levels under conditions of normoglycaemic and hyperglycaemic clamping. It can be seen that normoglycaemic levels were attained within $3.5 \mathrm{~h}$ of institution of GCIIS control. Thereafter the mean blood glucose level remained in the normal range. In the first $3.5 \mathrm{~h} 42 \pm$ 8 units insulin were given while $36 \pm 5$ units were required to maintain normoglycaemia thereafter. In the second study the desired hyperglycaemic levels were obtained more rapidly. In the first $3.5 \mathrm{~h} 18 \pm 9$ units insulin were given and only $19 \pm 7$ units were required thereafter (Fig. 1). At the same time 19.2 \pm $8.3 \mathrm{~g}$ glucose was infused over the $12 \mathrm{~h}$ period in the hyperglycaemic study. Two thirds $(13.0 \pm 7.0 \mathrm{~g})$ of this were infused over the $8 \mathrm{~h}$ period from noon to $20.00 \mathrm{~h}$. No glucose was administered to patients during normoglycaemic clamping.

\section{Blood Metabolite and Hormone Levels during Normoglycaemic and Hyperglycaemic Clamping}

Comparisons of hormones and metabolites were made for the period $12.00 \mathrm{~h}$ to $20.00 \mathrm{~h}$ during which stable blood glucose levels were maintained. Blood 


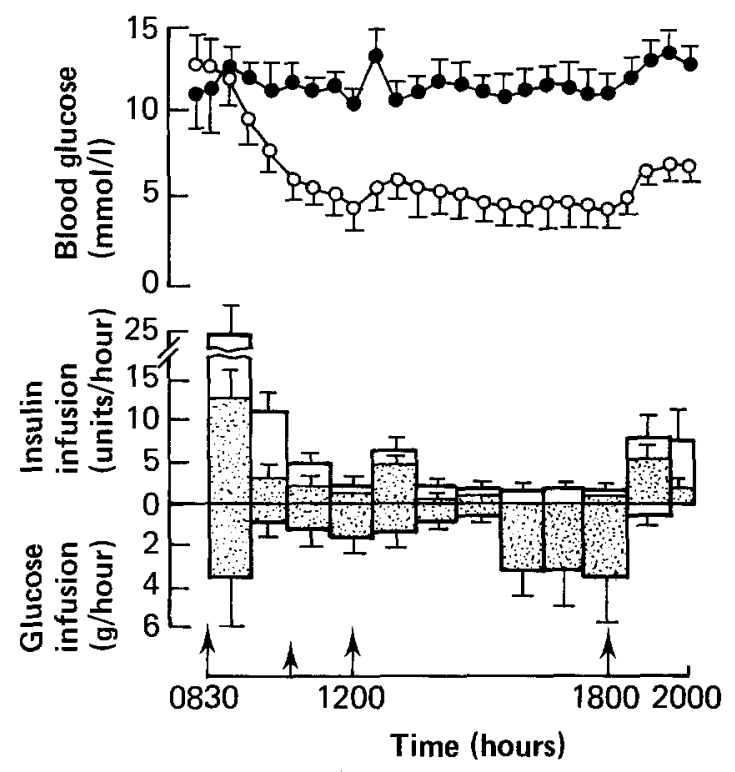

Fig. 1. Blood glucose concentration, and insulin and glucose infusion rates during normoglycaemic and hyperglycaemic clamping in insulin-dependent diabetic subjects. $\mathrm{O}-\mathrm{O}$ and open columns, normoglycaemic clamping; $\longrightarrow$ and stippled columns, hyperglycaemic clamping. Results shown \pm SEM. Meals given at times are indicated by large arrows and the snack by a small arrow

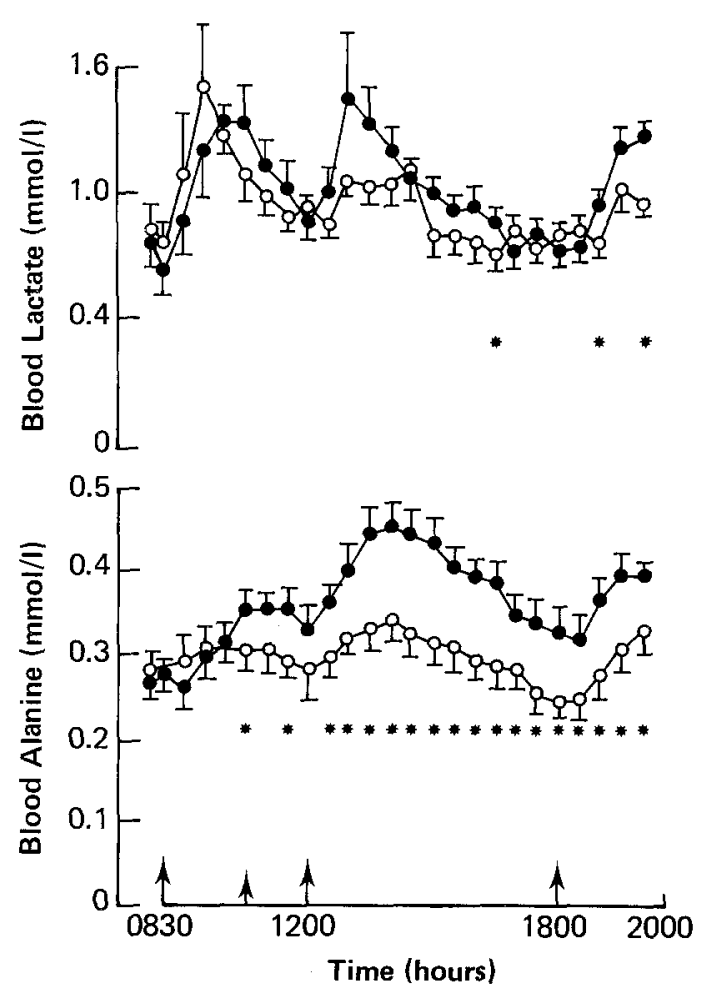

Fig. 2. Blood lactate and alanine concentrations during normoglycaemic and hyperglycaemic clamping. Symbols as in legend to Figure $1 .{ }^{*} \mathrm{p}<0.05$ for mean values at individual time points using the Student paired t-test lactate and pyruvate concentrations were not significantly different at the two glucose levels (Fig. 2). Mean values are shown in Table 2 . Similarly lactate/ pyruvate ratios were comparable. In contrast blood alanine levels were markedly and significantly higher throughout the study period during hyperglycaemic clamping compared with normoglycaemic clamping.

There were no significant differences in plasma NEFA, blood glycerol or total ketone body concentrations in the two situations although the mean 3hydroxybutyrate and 3-hydroxybutyrate/acetoacetate ratios were somewhat decreased during the final $8 \mathrm{~h}$ of hyperglycaemic clamping. Serum triglyceride levels were similar during the two clamping experiments. Serum growth hormone levels were slightly decreased $(p<0.05)$ during the hyperglycaemic clamping while there was a significant increase in mean plasma glucagon levels $(\mathrm{p}<0.01)$.

\section{Correlations}

Correlations were sought between the $8 \mathrm{~h}(12.00-$ $20.00 \mathrm{~h}$ ) mean values for different hormones and metabolites using data from both normoglycaemic and hyperglycaemic clamping experiments. Significant correlations are shown in Table 3 . It can be seen that the amount of insulin infused showed a negative correlation with mean plasma alanine values but infused insulin did not correlate with glucose levels, due presumably to the large intersubject variation in insulin requirement. Alanine levels also correlated with glucose $(\mathrm{p}<0.01)$, lactate $(\mathrm{p}<0.01)$ and negatively but modestly with 3 -hydroxybutyrate/acetoacetate $(\mathrm{p}<0.05)$.

\section{Discussion}

In the present study the effects of normoglycaemic and hyperglycaemic clamping on intermediary metabolism have been compared in diabetic subjects. To maintain the desired hyperglycaemic levels only half the amount of insulin was needed as was used for normoglycaemic clamping and additionally some glucose had to be infused. Considering the difference in glucose levels and presumably also free insulin levels perturbations of other carbohydrate intermediates were surprisingly lacking. Blood lactate and pyruvate levels were not different at the two glucose levels although it should be noted that levels were moderately raised as compared with normal subjects [3]. It is possible that the increased lactate levels found with normoglycaemic clamping are due to suppression of hepatic lactate uptake consequent upon an increased insulin level. This is unlikely in the hyperglycaemic 
Table 2. Mean \pm SEM $8 \mathrm{~h}(12.00-20.00 \mathrm{~h})$ metabolite and hormone concentrations in insulin-dependent diabetic subjects during normoglycaemic and hyperglycaemic clamping using a glucose controlled insulin infusion system

\begin{tabular}{|c|c|c|c|c|}
\hline \multirow[b]{2}{*}{ Blood glucose } & \multirow[b]{2}{*}{$\mathrm{mmol} / 1$} & $\begin{array}{l}\text { Normoglycaemic } \\
\text { clamp }\end{array}$ & $\begin{array}{l}\text { Hyperglycaemic } \\
\text { clamp }\end{array}$ & \multirow{2}{*}{$\begin{array}{l}\mathrm{p} \\
<0.001\end{array}$} \\
\hline & & $5.6 \pm 0.2$ & $12.1 \pm 0.2$ & \\
\hline Blood lactate & $\mathrm{mmol} / 1$ & $0.92 \pm 0.08$ & $1.02 \pm 0.05$ & NS \\
\hline Blood pyruvate & $\mathrm{mmol} / 1$ & $0.080 \pm 0.007$ & $0.090 \pm 0.007$ & NS \\
\hline Blood alanine & $\mathrm{mmol} / \mathrm{I}$ & $0.298 \pm 0.005$ & $0.382 \pm 0.006$ & $<0.01$ \\
\hline Blood glycerol & $\mathrm{mmol} / \mathrm{l}$ & $0.074 \pm 0.08$ & $0.075 \pm 0.013$ & NS \\
\hline Plasma NEFA & $\mathrm{mmol} / 1$ & $0.56 \pm 0.02$ & $0.61 \pm 0.03$ & NS \\
\hline Total blood ketone bodies ${ }^{a}$ & $\mathrm{mmol} / \mathrm{l}$ & $0.139 \pm 0.011$ & $0.125 \pm 0.010$ & NS \\
\hline 3-Hydroxybutyrate ${ }^{\mathrm{a}}$ & $\mathrm{mmol} / 1$ & $0.084 \pm 0.008$ & $0.068 \pm 0.007$ & $<0.05$ \\
\hline Acetoacetate & $\mathrm{mmol} / \mathrm{l}$ & $0.054 \pm 0.003$ & $0.058 \pm 0.003$ & NS \\
\hline Serum triglycerides & $\mathrm{mmol} / \mathrm{l}$ & $1.33 \pm 0.13$ & $1.47 \pm 0.10$ & NS \\
\hline Serum growth hormone & $\mu \mathrm{g} / 1$ & $2.6 \pm 0.4$ & $1.5 \pm 0.3$ & $<0.05$ \\
\hline Plasma glucagon & $\mathrm{pg} / \mathrm{ml}$ & $29 \pm 2$ & \pm 2 & $<0.01$ \\
\hline Lactate/pyruvate & & $11.6 \pm 0.2$ & \pm 0.1 & NS \\
\hline Alanine/pyruvate & & $3.9 \pm 0.1$ & \pm 0.1 & $<0.01$ \\
\hline 3-Hydroxybutyrate/ & & & & \\
\hline acetoacetate & & $1.4 \pm 0.1$ & $1.0 \pm 0.1$ & $<0.05$ \\
\hline
\end{tabular}

a Ketone body values were calculated on a logarithmic basis but are expressed arithmetically for ease of expression

Differences between groups were assessed using the Mann Whitney U-test

Total ketone bodies refers to the sum of 3-hydroxybutyrate and acetoacetate concentrations.

NS: $\mathrm{p}>0.05$

Table 3. Correlations between the mean eight hour $(12.00-20.00 \mathrm{~h})$ metabolite values and infused insulin. Values used include those from both hyperglycaemic and normoglycaemic clamping. Significance assessed using the Spearman Rank method

\begin{tabular}{llcl}
\hline Variable 1 & Variable 2 & $\begin{array}{l}\text { Correlation } \\
\text { coefficient }\end{array}$ \\
\hline Infused & & & \\
insulin & Blood alanine & -0.72 & $<0.01$ \\
Blood glucose & Blood alanine & 0.79 & $<0.01$ \\
Blood alanine & Blood lactate & 0.79 & $<0.01$ \\
Blood alanine & Blood (3-hydroxybutyrate) & -0.58 & $<0.05$ \\
\cline { 4 - 5 } & Blood (acetoacetate) & & \\
\hline
\end{tabular}

subjects where increased extrahepatic glycolysis and lactate production secondary to hyperglycaemia seem more likely.

In striking contrast to the similarity in lactate and pyruvate concentrations in the two situations, blood alanine levels were markedly elevated during hyperglycaemic clamping. This indeed was the only major metabolic difference found between hyperglycaemic and normoglycaemic clamping. The increase in alanine was positively correlated with glucose levels and negative correlated with the amount of insulin administered. The two main sites of regulation of alanine levels are the liver and peripheral tissues, particularly muscle [14]. Inhibition of alanine uptake by the liver seems unlikely. Inhibition of gluconeogenesis would be expected to have equal effects on lactate, pyruvate and alanine. Hepatic alanine uptake is also under the control of glucagon which enhances alanine uptake [15] but glucagon levels were raised in the hyperglycaemic subjects (Table 2).

A peripheral mechanism for the hyperalaninaemia must therefore be sought. Alanine is released in large amounts from muscle in particular as part of the glucose-alanine cycle [14]. Approximately $30 \%$ of the released alanine is derived directly from protein while the rest comes from transamination of pyruvate $[16,17]$, with 60 to $80 \%$ of alanine carbon derived from glucose [18]. Recently Liljenquist et al. [19] have investigated the effects of hyperglycaemia on alanine metabolism in fasting dogs. They showed that hyperglycaemia per se increased net inflow of alanine into blood independent of changes in insulin and glucagon levels, and with no change in hepatic alanine uptake. Similarly Waterhouse and Keilson [20] have shown that in man, after an overnight fast, twice as much carbon from glucose is cycled to alanine as is returned to glucose from alanine. In addition the magnitude of the contribution of carbon skeletons to alanine from glucose is dictated by the rate of glycolysis. Our results are in keeping with the hypothesis that high levels of glucose together with low levels of insulin, increase the flow of glucose carbon into alanine. The increase in amino groups must come from proteolysis but the mechanism for this remains to be elucidated. 
Despite the greatly diminished insulin input in the hyperglycaemic situation, there was no increase in circulating fatty acid, glycerol or ketone body levels. Adipose tissue is exquisitely sensitive to insulin [21] and presumably there was sufficient insulin available to maintain lipolysis at normal levels. Ketone body levels were, if anything, decreased with 3-hydroxybutyrate significantly lowered, which would not be predicted from the decreased insulin and increased glucagon: insulin ratios.

Although circulating NEFA levels are the main determinants of hepatic ketogenesis it is possible that alanine may have contributed to the lower 3-hydroxybutyrate levels. Ozand et al. [22, 23] using young rats, have shown that alanine infusion can lower blood ketone body levels. We have shown that this is a direct effect on hepatic ketogenesis and may be due to an increase in oxaloacetate availability [24].

In conclusion, acute clamping of blood glucose at raised levels in diabetics is accompanied by less metabolic perturbations than might be expected, when compared with the results of normoglycaemic clamping in the same subjects. The most notable findings were an increase in alanine levels and the lack of change in ketone body and NEFA levels.

Acknowledgements. We gratefully acknowledge financial support from the British Diabetic Association. RN thanks the British Council and Novo Industries for personal support. We are indebted to Drs. M. Nattrass, D. G. Johnston, A. L. J. Buckle and A. H. Clemens for advice and encouragement, to Ms. A. Cornell, B. Lloyd and P. Smythe for technical assistance and to Dr. C. Binder for C-peptide measurement.

\section{References}

1. Hansen AaP, Johansen K (1970) Duirnal patterns of blood glucose, serum free fatty acids, insulin, glucagon and growth hormone in normals and juvenile diabetics. Diabetologia 6: 2.7-33

2. Alberti KGMM, Dornhorst A, Rowe AS (1975) Metabolic rhythms in normal and diabetic man. Isr J Med Sci 2: 571-580

3. Nattrass M, Alberti KGMM, Buckle ALJ, Cluett BE, Noy GA, Stubbs WA, Walton R (1979) Metabolic studies during normoglycaemic clamping of insulin dependent diabetics using a glucose controlled insulin infusion. In: Hepp KD, Kerner W, Pfeiffer EF (ed) Feedback controlled and preprogrammed insulin infusion in diabetes mellitus. Horm Metab Res [Suppl] 8: $86-92$

4. Clemens AH (1979) In: Drouin P, Mejean L, Debry G (eds) Artificial pancreas, clinical applications. Doin Editeurs, Paris 61-75

5. Lloyd B, Burrin J, Smythe P, Alberti KGMM (1978) Enzymic fluorimetric continuous flow assays for blood glucose, lactate, pyruvate, alanine, glycerol and 3-hydroxybutyrate. Clin Chem 24: 1724-1729

6. Price CP, Lloyd B, Alberti KGMM (1977) A kinetic spectrophotometric assay for rapid determination of acetoacetate in blood. Clin Chem 23: 1893-1897
7. Ho RJ, Meng HC (1969) A simple and ultrasensitive method for determination of free fatty acid by radiochemical assay. Anal Biochem 31: 426-436

8. Ørskov H, Thomson HG, Yde H (1968) Wick chromatography for rapid and reliable immunoassay of insulin, glucagon and growth hormone. Nature 219: 193-195

9. Boden G, Soeldner JS (1976) A sensitive double antibody radioimmunoassay for human growth hormone (HGH): levels of serum HGH following rapid tolbutamide infusion. Diabetologia $13: 413-421$

10. Postle AK, Goodland FC (1977) Comparison of three automated methods of serum triglyceride analysis. Ann Clin Biochem 13: 438-448

11. Faber OK, Binder C, Markussen J, Heding LG, Naithani VK, Kuzuya H, Blix P, Horwith DL, Rubenstein AH (1978) Characterization of seven C-peptide antisera. Diabetes 27 (Suppl 1]: 170-177

12. Foster KJ, Alberti KGMM, Hinks L, Lloyd B, Postle A, Smythe P, Turnell DC, Walton R (1978) Blood intermediary metabolite and insulin concentrations after an overnight fast: reference ranges for adults and interrelations. Clin Chem 24: $1568-1572$

13. Snedecor GW, Cochran WG (1976) Statistical methods. Iowa University Press, Ames

14. Felig P (1973) The glucose-alanine cycle. Metabolism 22: $179-207$

15. Mallette LR, Exton JH, Park CR (1969) Effects of glucagon on aminoacid transport and utilisation in the perfused rat liver. J Biol Chem 244: 5724-5728

16. Blackshear PJ, Holloway PAH, Alberti KGMM (1975) Factors regulating amino acid release from extrasplanchnic tissues in the rat. Biochem J 15: 379-387

17. Snell K, Duff DA (1977) The release of alanine by rat diaphragm muscle in vitro. Biochem J 162: 399-403

18. Odessey R, Khairallah EA, Goldberg AL (1974) Origin and possible significance of alanine production by skeletal muscle. J Biol Chem 249: 7623-7629

19. Liljenquist JE, Shulman GI, Williams PE, Lacy WW, Cherrington AA (1979) Hyperglycaemia per se is an important regulator of alanine and lactate metabolism. Waldhäusl W, Alberti KGMM (eds) 10th Congress of the International Diabetes Federation. International Congress Series 481. Excerpta Medica, Amsterdam, p 141

20. Waterhouse C, Keilson J (1978) The contribution of glucose to alanine metabolism in man. $\mathrm{J}$ Lab Clin Med 92: 803-812

21. Zierler KL, Rabinowitz D (1963) Role of insulin and growth hormone, based on studies of forearm metabolism in man. Medicine (Baltimore) 42: 385-402

22. Ozand PT, Reed WD, Girard $J$, Hawkins RL, Collins RM, Tildon JT, Cornblath M (1977) Hypoketonaemic effect of alanine. Specific decrease in blood concentrations of 3-hydroxybutyrate in the rat. Biochem J 164: 557-564

23. Ozand PT, Reed WD, Hawkins RL, Stevenson JH, Tildon JT, Cornblath M (1978) Effect of L-alanine infusion on gluconeogenesis and ketogenesis in vivo. Biochem $\mathrm{J} 170$ : $583-591$

24. Nosadini R, Datta H, Hodson A, Alberti KGMM (1980) Antiketogenic action of alanine in the rat: possible mechanism. Biochem J 190: 323-332

Received: April 11, 1980,

and in revised form: September 30, 1980

Prof. K. G. M. M. Alberti

Department of Clinical Biochemistry and Metabolic Medicine Newcastle upon Tyne NEI 4LP

England 